Environmental Research Journal 5 (4): 163-169, 2011

ISSN: 1994-5396

(C) Medwell Journals, 2011

\title{
Failure Evaluation of Aluminum Alloy in 2 M Hydrochloric Acid in the Presence of Cola acuminata
}

\author{
${ }^{1}$ O.O. Ajayi, ${ }^{1}$ O.A. Omotosho, ${ }^{2}$ K.O. Ajanaku and ${ }^{1}$ B.O. Olawore \\ ${ }^{1}$ Department of Mechanical Engineering, ${ }^{2}$ Department of Chemistry, \\ Covenant University, P.M.B. 1023 Ota, Nigeria
}

\begin{abstract}
Hydrochloric acid induced damage of aluminum alloy in the presence of Cola acuminata extract was investigated using gasometric technique. Aluminum alloy coupons of dimension $4 \mathrm{~cm}$ by $1 \mathrm{~cm}$ were immersed in test solutions of free acid and also those containing extract concentrations of $2-5 \mathrm{~cm}^{3}$ at ambient temperature for $30 \mathrm{~min}$. The volumes of hydrogen gas evolved as a result of the reaction rate were recorded and analyzed. The outcome revealed that maximum inhibitor efficiency which corresponds to the lowest corrosion rate was obtained at optimum inhibitor concentration with reduction in the corrosion rate observed to follow in order of increasing extract concentration. The mechanism of interaction between the phytochemicals in the plant extract and aluminum alloy surface was best described by the Frumkin isotherm with 6 and 14 min becoming the best exposure time for the phytochemicals in extract concentrations of $3-5 \mathrm{~cm}^{3}$ to suitably adsorb to metal alloy surface. Statistically modeling the corrosion rate yielded a significant relationship suitable for estimating corrosion rate values once concentration of the extract is known. In addition, the superficial analysis revealed that crack growth rate slowed down and irregular intermetallic phases were more uniform as extract concentration increased.
\end{abstract}

Key words: Environmentally induced cracking, green inhibitors, hydrogen evolution, regression analysis, aluminum alloy, Nigeria

\section{INTRODUCTION}

Aluminum (Al) and its alloys have low atomic weight, high strength to density ratio, high ductility and an excellent heat and electricity conductor. These properties make Al alloys very useful for construction of parts in the automotive, aerospace and chemical industries (Roberts and Caserio, 1979; Haque and Maleque, 1998; Haque and Sharif, 2001; Mishra and Balasubramaniam, 2007). It is also pertinent to note that $\mathrm{Al}$ is also prone to corrosion due to its negative standard potential of $-1.66 \mathrm{~V}$ vs. NHE (Diaz-Ballote et al., 2009). This susceptibility to attack is observed in oil well acidizing, pickling, cleaning and descaling operations where the metal is exposed to hydrochloric or sulfuric acid once the protective oxide layer is destroyed. These aggressive agents are used to remove dirts, mill and oxide scales and the products of the resulting reaction are $\mathrm{Al}$ ions, hydrogen $\left(\mathrm{H}_{2}\right)$ gas and toxic acid vapour. There is also, in some instances depending on the exposure duration, extensive material wastage which reduces strength and induces cracks that ultimately leads to the catastrophic failure of the component. Even though, the deterioration behavior of $\mathrm{Al}$ and its alloys has been extensively studied in aqueous solutions containing different aggressive species and $\mathrm{pH}$ using different organic compounds as inhibitors however, only little attention has been given to the use of an eco-friendly inhibitor to reduce the toxic properties and limited solubility of the organic compounds being used as inhibitors (El-Etre, 2003; Oguzie, 2005).

More so, increasing environmental awareness of health and ecological risks has drawn attention to finding more suitable inhibitors which are non-toxic and environmentally benign. Previous studies reported the successful uses of Vanilla opuntia, Rosinarinus officinalis extracts as corrosion inhibitors of $\mathrm{Al}$ in different media (Abiola et al., 2004). This awareness has led to the development of eco-friendly inhibitors with focus on the corrosion retarding properties of non-toxic materials of which natural products from plant origins are inclusive. Some of these natural products have their retarding effect attributed to the presence of tannins in their chemical constituents. Tannins exhibit a dual corrosion retarding action via: formation of a protective oxide film and tannate as the anodic sites of the corroded surface (Abiola, et al., 2007). Extracts of Azadirachta indica, Vernonia amygdalina Cocos nucifera,

Corresponding Author: O.O. Ajayi, Department of Mechanical Engineering, Covenant University, P.M.B. 1023 Ota, Nigeria 
Rosmarinus officinalis, Occimum viridis, Ocimum basilicium and Allium sativum (Abiola and Okafor, 2003; Orubite and Oforka, 2004; Abdel-Gaber et al., 2006; Assaf et al., 2007; Umoren et al., 2008, 2009) amongst others have been reported to have inhibitive effect on the rate of corrosion of metals in acidic and basic media.

The main emphasis of this study is to investigate the deterioration behavior of $\mathrm{Al}$ alloy exposed to extract of Cola acuminata (CA) at different concentrations using gasometric method of measurement unlike previous studies that deduced corrosion rate from weight loss measurements. CA belongs to the natural order Sterculiaceae. The tree is a native of west tropical Africa. It is a tree 20-30 feet high with cylindrical smooth branches. The flowers are numerous, polygamous and arranged in terminal and auxillary cymose panicles. The fruit normally consists of five pods each one is about 3-6 inches long and 2-3 inches thick (Iwu, 1993).

The technique adopted in this study was based on the hypothesis that the rate at which metal is wasted after exposure corresponds to the rate of evolution of $\mathrm{H}_{2}$ gas since it was discovered that increased metal loss resulted in rapid rate of evolution of hydrogen gas. It is well known that when metals in service corrode in the presence of acids, $\mathrm{H}_{2}$ gas is constantly evolved. The rate at which the $\mathrm{H}_{2}$ gas is evolved corresponds to the rate of metal dissolution in the environment, depicted by weight loss. Thus if there is a way to measure the volume of $\mathrm{H}_{2}$ gas evolved as a relationship with the metal mass loss, the rate of corrosion of the metal within the environment can directly be simulated without necessarily leading to plant downtime. This will enable the engineers to have a pre-knowledge of the situation and know when to carry out specific type of repair. The focus of this study therefore is to establish the relationship between corrosion rate and the rate of evolution of $\mathrm{H}_{2}$ gas as well as determine other essential parameters that correlate metal surface phenomenon in a particular environment. The Al degradation behavior was also studied using the Freundlich, Langmuir, Frumkin, Boris-Swinkels and Temkin adsorption isotherms in order to determine the best adsorption mechanism.

\section{MATERIALS AND METHODS}

Specimens of aluminum metal coupon of dimension $4 \times 1 \mathrm{~cm}$ were employed for the determination of corrosion inhibition of Cola acuminata (CA) extract. The samples were prepared by degreasing the coupons in ethanol and acetone. It was then allowed to dry. The composition of the $\mathrm{Al}$ samples was analyzed using Optical Emission
Spectrometer (OES) and the result as obtained were (wt $\%$ ), Silicon $(0.157 \%)$, Cadmium $(0.0005 \%)$, Iron $(0.282 \%)$, Calcium $(0.0011 \%)$, Copper $(0.0025 \%)$, Cobalt $(<0.0010 \%)$, Manganese $(0.024 \%)$, Lithium $(<0.0002 \%)$, Magnesium (0.51\%), Sodium (0.0005\%), Zinc $(<0.0010 \%)$, Phosphorous $(<0.0010 \%)$, Nickel $(<0.0010 \%)$, Lead $(<0.0005 \%)$, Chromium $(0.023 \%)$, Tin $(<0.0010 \%)$, Titanium $(0.0049 \%)$, Strontium $(<0.0001 \%)$, Silver $(<0.0001 \%)$, Vanadium $(0.0035 \%)$, Boron $(0.0007 \%)$, Zirconium $(0.0020 \%)$, Beryllium $(<0.0001 \%)$, Al $(99 \%)$ Bismuth $(<0.0010 \%)$.

The acidic extracts of CA were prepared from its fresh leaves after it has been air dried and ground into powder. The $10 \mathrm{~g}$ of the powder was then put into a flat bottom flask containing $200 \mathrm{~cm}^{3}$ of $2 \mathrm{M} \mathrm{HCl}$ solution. The resulting solution was refluxed for $2 \mathrm{~h}$ and left over night before it was filtered. Extract concentrations of $2-5 \mathrm{~cm}^{3}$ obtained by serial dilution were employed for the investigation. The experimental set up is similar to the set up in literature (Ajayi et al., 2011). Each specimen was dropped into the mylius cell containing $50 \mathrm{~cm}^{3}$ of test solution system at room temperature. The volume of $\mathrm{H}_{2}$ gas evolved per $120 \mathrm{sec}$ interval was recorded for $30 \mathrm{~min}$ in a calibrated tube by downward displacement of water and the plot of volume against the time interval was carried out and showed in Fig. 1. The inhibition efficiency was then determined using Eq. 1 (Okafor et al., 2010):

$$
\mathrm{I} . \mathrm{E}(\%)=\frac{\left(\mathrm{V}_{\mathrm{H}}-\mathrm{V}_{\mathrm{HI}}\right)}{\mathrm{V}_{\mathrm{H}}} \times 100
$$

where, $\mathrm{V}_{\mathrm{H}}$ is the volume of hydrogen evolved without inhibitor (i.e., control experiment) and $\mathrm{V}_{\mathrm{H} 1}$ is the volume of hydrogen evolved with inhibitor.

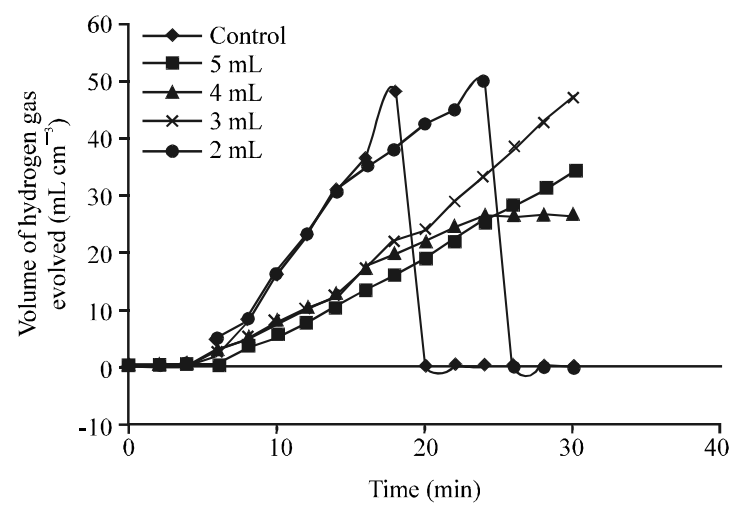

Fig. 1: Variation of volume of hydrogen $\left(\mathrm{cm}^{3}\right)$ evolved with time ( $\mathrm{min}$ ) of $\mathrm{Al}$ coupons for different concentrations of $\mathrm{CA}$ extract in $2 \mathrm{M} \mathrm{HCl}$ at room temperature 
Moreover since, $\mathrm{Al}$ alloy reacts with $\mathrm{HCl}$ in such a way that $\mathrm{H}_{2}$ gas is given off as one of the product of reaction, it is therefore suitable to predict the rate of reaction by determining the rate of evolution $\mathrm{H}_{2}$ gas from the system. It is therefore, straight forward to say that the rate of reaction corresponds to the rate of corrosion damage of the $\mathrm{Al}$ alloy in $\mathrm{HCl}$ in the presence of $\mathrm{CA}$ extract. Thus, the rate of corrosion corresponding to the rate of hydrogen evolution was modeled based on the idea that the rate of hydrogen gas evolution is directly proportional to the rate of corrosion which will also be directly proportional to the rate at which the weight of the metal is lost. The approach adopted in this study to develop a relationship between volume of hydrogen evolved and rate of metal wastage was obtained from literature (Ajayi et al., 2011) and the basis for this is as represented in Eq. 2.

$$
\mathrm{R} \alpha \frac{\mathrm{d} \Delta \mathrm{W}}{\mathrm{dt}} \alpha \frac{\mathrm{dV}}{\mathrm{dt}}
$$

Where:

$\alpha \quad=$ Proportionality sign

$\Delta \mathrm{V}=$ Volume of hydrogen gas evolved

$\Delta \mathrm{W}=$ Metal weight loss due to corrosion

$\mathrm{R}=$ Rate of corrosion

$\mathrm{t}=$ Time $(\mathrm{sec})$

Thus to determine Eq. 2, it is necessary to develop a relationship between volume evolved and the time of evolution. This was arrived at by a polynomial regression analysis of the volume of hydrogen gas against time leading to Eq. 3 (Ajayi et al., 2011):

$$
\mathrm{V}=\mathrm{c}+\mathrm{bt}+\mathrm{at}{ }^{2}
$$

Thus:

$$
\mathrm{R}=\frac{\mathrm{dV}}{\mathrm{dt}}=\mathrm{b}+2 \mathrm{at}
$$

Adapting Eq. 3 and 4 to the volume-time measurement for individual concentration and using the example for measurements relating to $5 \mathrm{~cm}^{3}$ extract concentration, the corrosion rate model is presented as Eq. 6:

$$
\begin{gathered}
V=-1.70+0.54 t+0.023 t^{2} \\
\frac{d V}{d t}=0.54+0.046 t
\end{gathered}
$$

\section{RESULTS AND DISCUSSION}

Figure 1 showed that the corrosion rate of $\mathrm{Al}$ alloy as indicated by the amount of hydrogen evolved decreased in the presence of CA when compared to the control. The $2 \mathrm{~cm}^{3}$ extract showed the highest increase in volume of hydrogen evolved when compared to the other extract concentration with values very close to the control. This may be as a result of the inhibitor concentration not being enough to assuage corrosion effectively. The amount of hydrogen evolved also decreased with extract concentration of $3-5 \mathrm{~cm}^{3}$ with the $5 \mathrm{~cm}^{3}$ extract showing the highest decrease throughout the experiment. This indicates that the $\mathrm{CA}$ extract in the solution has an inhibitive effect on the corrosion of $\mathrm{Al}$ in $\mathrm{HCl}$ and that the extent of inhibition depends on the amount of CA extract present. This same trend was similarly shown in Fig. 2 which shows the percentage inhibition efficiency (I.E\%). However, the I.E.\% readings of the $2 \mathrm{~cm}^{3}$ extract were observed to be very low when compared to the other extract concentration. This may be as a result of the fact that an acceleration of the rate of corrosion occurred due to insufficient inhibitor concentration with values being very similar to that of control as shown in Fig. 1. The performance of the 3 and $4 \mathrm{~cm}^{3}$ solution were closely related from the beginning until the 18 th min after which both plunged lower with the $3 \mathrm{~cm}^{3}$ going even lower probably due to its lower concentration till the end of the experiment.

However, the $5 \mathrm{~cm}^{3}$ extract performed effectively throughout the experimental period with I.E.\% peaking at the 6 th min of the experiment while I.E.\% peaked at the 14 th min for the 3 and $4 \mathrm{~cm}^{3}$ solution. Apparently the extract had formed a passive film on the metal surface indicating that the period for optimal performance was between 6 th and 14 th min.

Furthermore, from Fig. 3 it was observed that the rate of corrosion generally decreases in the presence of $\mathrm{CA}$ extract. The $2 \mathrm{~cm}^{3}$ extract of CA shows the lowest effect of reducing the corrosion rate of aluminum followed by the $3 \mathrm{~cm}^{3}$ extract. The $5 \mathrm{~cm}^{3}$ extract however began by slowing down the rate but towards the latter part of the reaction, the rate tends to increase above the 2 and $3 \mathrm{~cm}^{3}$ extract concentration. The reduction in corrosion rate in the

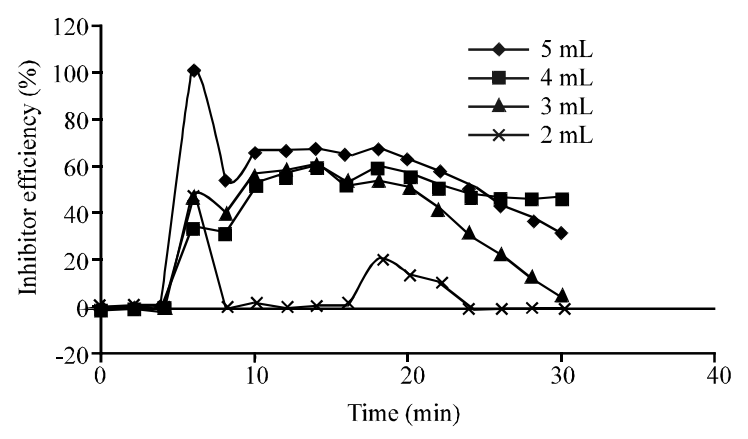

Fig. 2: Percentage inhibition efficiency of varying concentration of CA extracts with time (min) on $\mathrm{Al}$ coupon in $2 \mathrm{M} \mathrm{HCl}$ solution at ambient temperature 


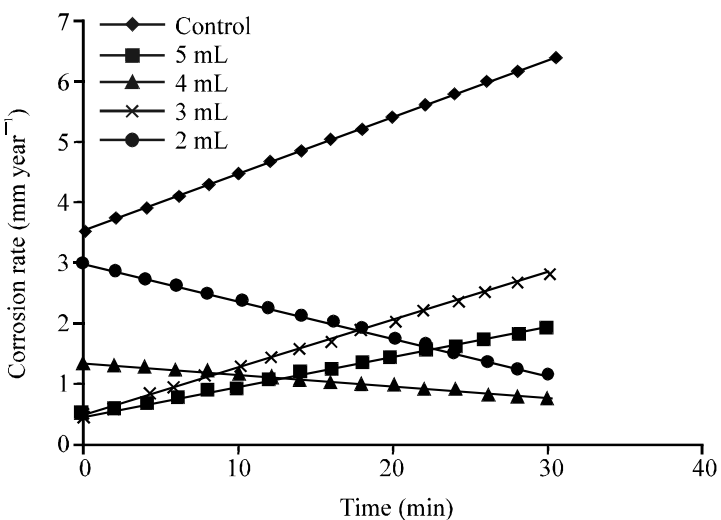

Fig. 3: Corrosion rate of varying concentrations of CA extract with time (min) on $\mathrm{Al}$ coupon in $2 \mathrm{M} \mathrm{HCl}$ solution at room temperature

presence of CA extract at different concentrations was observed to follow the order; $2 \mathrm{~cm}^{3}$ extract $<3 \mathrm{~cm}^{3}$ extract $<5 \mathrm{~cm}^{3}$ extract $<4 \mathrm{~cm}^{3}$ extract.

Further investigating the relationship between corrosion rate, $\mathrm{R}$ and the changing concentration to obtain reaction constant and also the specific reaction constant for the $\mathrm{HCl}$ corrosion of $\mathrm{Al}$ alloy in the presence of CA extract involved carrying out a statistical regression analysis of the values of $\mathrm{R}$ against those of concnetration. However, it has been established (Mathur and Vasudevan, 1982; Noor and Al-Moubaraki, 2008; Ajayi et al., 2011) that corrosion rates can be correlated with acid concentration with Eq. 7 :

$$
\log \mathrm{R}=\log \mathrm{k}+\mathrm{BLog} \mathrm{C}
$$

Where:

$$
\begin{aligned}
& \mathrm{R}=\text { Corrosion rate } \\
& \mathrm{k}=\text { Reaction constant } \\
& \mathrm{B}=\text { Specific reaction constant } \\
& \mathrm{C}=\text { Concentration }
\end{aligned}
$$

Therefore to obtain reaction constant, the corrosion rates obtained from $\mathrm{H}_{2}$ evolution method must be converted to the same unit $\left(\mathrm{mol} \mathrm{min}^{-1}\right)$ by assuming that $\mathrm{H}_{2}$ evolution reaction occurred at $1.01325 \times 10^{-5} \mathrm{~Pa}$. Figure 4 shows the relationship between Log R and Log $\mathrm{C}$ for the $\mathrm{Al}$ alloy coupon sample. The straight line in the graph correlates all the points with correlation coefficient of 0.105 . The estimated $\mathrm{k}$ and $\mathrm{B}$ values were $4.518 \times 10^{-7} \mathrm{~mol} \mathrm{~min}^{-1}$ and -0.116 . In contrast to the positive value of $\mathrm{B}$ obtained in other studies (Mathur and Vasudevan, 1982; Noor and Al-Moubaraki, 2008) when no inhibitors were used, the negative value of $\mathrm{B}$ indicate a decreasing slope which significantly depicts the inhibitive action of the $\mathrm{CA}$ extract on the Al-alloy corrosion. Thus the exact relationship can be described as:

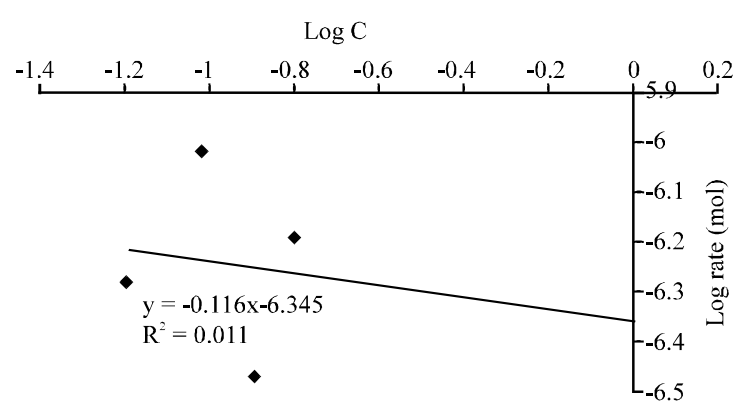

Fig. 4: Plot of $\log$ of corrosion rate against $\log$ of the acid extract concentration

$$
\mathrm{R}=4.518 \times 10^{-7} \mathrm{C}^{-0.116}
$$

This is in accord with Fig. 3 where a clear cut difference was noted between the control and inhibited solutions.

Adsorption studies: The interaction mechanism between the phytochemicals in the CA extract and the metal surface can be justified using various adsorption isotherms namely Freundlich, Langmuir, Frumkin, BorisSwinkels and Temkin. The degree of surface coverage, $\theta$ for the different inhibitor concentrations were evaluated based on volume of $\mathrm{H}_{2}$ gas evolved measurements. Also, the degree of corrosion inhibition depends on the surface conditions and mode of adsorption of inhibitors. The experimental data were then made to fit with the different adsorption isotherms and the Frumkin isotherm was found to be best fitted to the $\theta$ values. The Frumkin isotherm relationship (El-Sayed et al., 2010) is represented as:

$$
\operatorname{Ln}\left(\frac{\theta}{C(1-\theta)}\right)=\operatorname{Ln} \Psi+2 \rho \theta
$$

Where:

$$
\begin{aligned}
\theta= & \text { Surface coverage } \\
\mathrm{C}= & \text { Concentration of inhibitor } \\
\Psi= & \text { Binding constant of the adsorption reaction } \\
\rho= & \text { Lateral interaction term describing the molecular } \\
& \text { interactions in the adsorption layer and the } \\
& \text { heterogeneity of the surface (it is a measure for } \\
& \text { the steepness of the adsorption isotherm) }
\end{aligned}
$$

This was achieved by performing a linear regression analysis of $\operatorname{Ln}(\theta / C(1-\theta))$ against $\theta$ to determine the exact relationship between $\operatorname{Ln}(\theta / C(1-\theta))$ and $\theta$ as shown in Fig. 5. This resulted in Eq. 10:

$$
\mathrm{Y}=3.562 \mathrm{x}+0.255\left(\mathrm{R}^{2}=94.2 \%\right)
$$




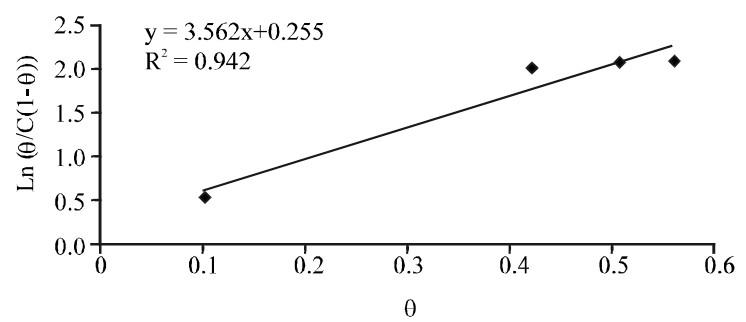

Fig. 5: Variation of $\operatorname{Ln}(\theta / C(1-\theta))$ with surface coverage ( $\theta)$ of acid extract showing compliance with Frumkin isotherm

In order to obtain values for $\Psi$ and $\rho$, a comparison of Eq. 10 with the Frumkin isotherm relationship is necessary. Therefore:

$$
\begin{gathered}
\operatorname{Ln} \Psi=0.255 \\
\psi=e^{0.255}=1.29 \\
\rho=\frac{3.562}{2}=1.781
\end{gathered}
$$

The relatively low value of $\Psi$, suggests that the investigated inhibitor is physically adsorbed on the surface of Al alloy while the positive value of $\rho$ implies that the interaction between the molecules enhances the adsorption energy with the increase of $\theta$.

More so, the degree of surface coverage, $\theta$ for the extract at different concentrations was plotted for time intervals of $6,8,10,14,18$ and $22 \mathrm{~min}$ as shown in Fig. 6 to investigate if there are any influence of times of exposure to the relationship between $\theta$ and $C$.

For the $8 \mathrm{~min}$ curve, the $\theta$ value was very low at extract concentration of $2 \mathrm{~cm}^{3}$ but it increased rapidly, first to 0.4 and then further until it reached the optimum value of 0.5375 . This shows that the $\mathrm{Al}$ alloy experienced the lowest surface coverage by the phytochemicals in the extract at the exposure time of $8 \mathrm{~min}$. However, the other exposure times showed higher $\theta$ values with the 6 and 14 min exposure times showing the highest value of surface coverage, though the values for the 10 and $14 \mathrm{~min}$ curves were closely related. This means that during the 6 and 14 min time frames surface coverage of CA extract at different concentrations was the best. The $\theta$ values displayed during the $6 \mathrm{~min}$ time frame was the highest across all the concentration showing that this time frame is the best for the phytochemicals to adsorb to the Al alloy surface and inhibit corrosion effectively. This further corroborates the assertion in Fig. 2 that clearly indicates that the peak I.E (\%) value was at $6 \mathrm{~min}$ for the $5 \mathrm{~cm}^{3}$ extract and $14 \mathrm{~min}$ for the 4 and $3 \mathrm{~cm}^{3}$ extract concentration employed in the study.

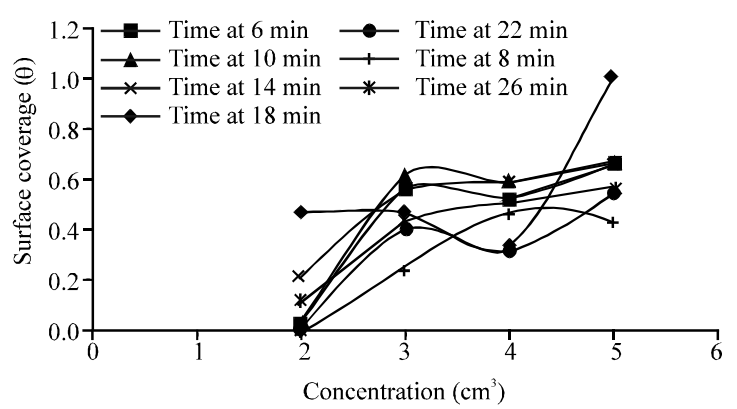

Fig. 6: Variation of surface coverage $(\theta)$ with extract concentration $(\mathrm{M})$ at different time intervals

The surface effects of the $\mathrm{HCl}$ action on the metal in the presence of CA extract were investigated using optical microscope. Also, the photomicrograph studies were performed on these samples in order to evaluate the condition of the $\mathrm{Al}$ alloy surface and grain structure. However, the investigation were carried out on three metal samples which include that of the control experiment (having no inhibitor present), sample from the 3 and $4 \mathrm{~cm}^{3}$ extract concentration. These were chosen to study the phenomenon on the case scenario of direct $2 \mathrm{M} \mathrm{HCl}$ attack, the least and highest inhibitive effect scenarios, knowing that all others will fall within these limits. More so, the values of the various indicators that characterized the behavior of samples in the 2 and $3 \mathrm{~cm}^{3}$ extract as well as 4 and $5 \mathrm{~cm}^{3}$ extract were closely related after immersion. Superficial analysis was carried out and the micrograph of the alloy before immersion as shown in Fig. 7a indicate the presence of three phases which were the $\alpha$-Al (white) phase, the $\mathrm{Mg}_{5} \mathrm{Al}_{8}$ (grey) phase and the thick spotted coarse $\mathrm{Mg}_{2} \mathrm{Si}$ (black) phase. The first two mentioned phases were observed to be finely dispersed. In Fig. 7b which is the control sample, the micrograph indicate the presence of irregular flakes of the intermetallic phase along the grain boundaries which eventually resulted in intergranular cracks. The influence of 3 and $4 \mathrm{~cm}^{3}$ acid extract of CA for $30 \mathrm{~min}$ on the aluminum specimen as shown in Fig. $7 \mathrm{c}$ and $\mathrm{d}$, respectively indicate that corrosion attack reduced with both extract concentration, though more prominent in the $4 \mathrm{~cm}^{3}$ extract. In addition, there were no major crack lines in both instances, but the alpha phase is more dispersed in the Fig. $7 \mathrm{~d}$ than in Fig. $7 \mathrm{c}$ while the second phase is more dispersed in the Fig. $7 \mathrm{c}$ than in Fig. 7d. Apparently intergranular and pitting corrosion may not have occured rather there were evidence of prominent grain coarsening and/or restructuring. The apppearance of surface flakes was less with increasing concentration of inhibitors than without. It was also discovered that the irregular intermetallic phases were more uniform after exposure to increasing 
(a)

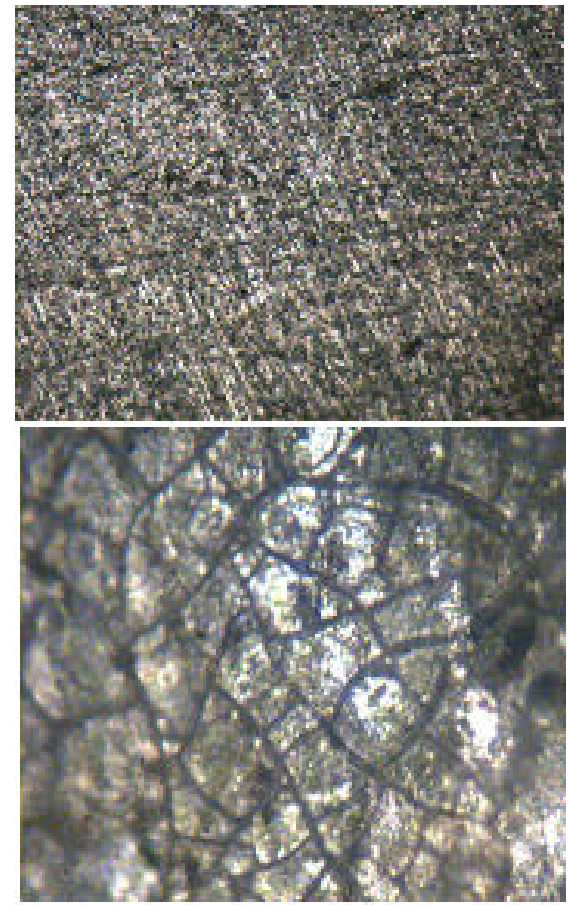

(c)

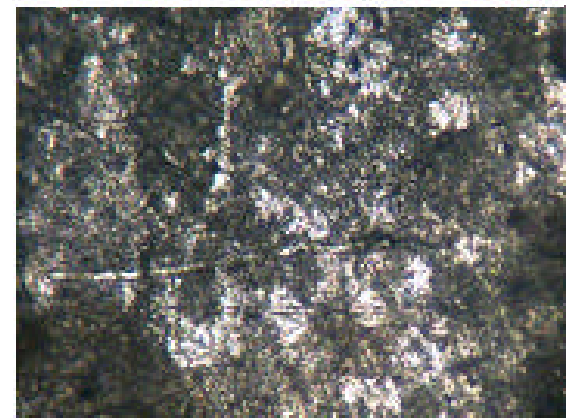

(d)

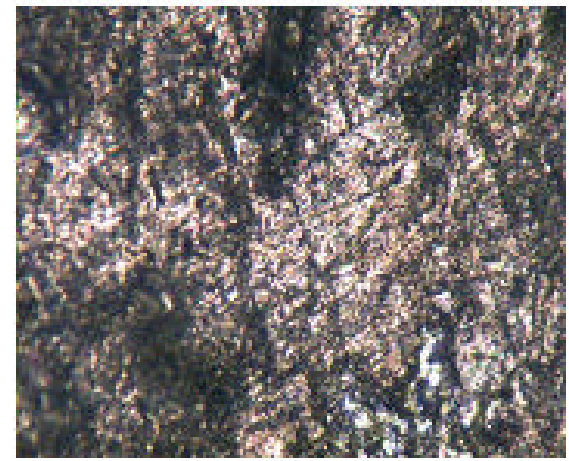

Fig. 7: Micrographs for aluminum surface (a) before immersion in $2 \mathrm{M} \mathrm{HCl}$ solutions (b) after immersion in $2 \mathrm{M} \mathrm{HCl}$ for $30 \mathrm{~min}$ (c) after immersion in $3 \mathrm{~cm}^{3}$ of CA extract for $30 \mathrm{~min}$ (d) after immersion in $4 \mathrm{~cm}^{3}$ of CA extract for $30 \mathrm{~min}$

concentration of inhibitors due to the adsorption efficiency of the CA extract which controls the acidic and cathodic reaction that may affect the grain structure.
Therefore, by comparing Fig. $7 \mathrm{c}$ and $\mathrm{d}$, it is observed that the addition of CA extract has apparently slowed down the crack growth rate and the higher the extract concentration the slower the crack growth rate and the longer the life of the alloy.

\section{CONCLUSION}

The study examined and evaluated the damage of Al alloy by $\mathrm{HCl}$ acid in the presence of $\mathrm{CA}$ extract using gasometric technique. The various indicators that characterized the behavior of the alloy in the medium at different inhibitor concentration were highlighted and a new relationship that represents a major contribution to corrosion rate measurement was also obtained. Investigations revealed that maximum I.E\% and lowest corrosion rate were obtained at optimum extract concentration of $5 \mathrm{~cm}^{3}$. The mechanism of interaction between the phytochemicals in the plant extract and $\mathrm{Al}$ alloy surface was best described by the Frumkin isotherm. The 6 and $14 \mathrm{~min}$ time frame was also revealed as the best time for the phytochemicals in the extracts at $3-5 \mathrm{~cm}^{3}$ concentrations to suitably adsorb to alloy surface. Statistical modeling of corrosion rate yielded a significant relationship suitable for estimating corrosion rate once concentration of CA extract is known. The superficial analysis revealed that crack growth rate slowed down and irregular intermetallic phases were more uniform as extract concentration increased which is in agreement with the initial inference of lowest corrosion rate at optimum extract concentration.

\section{REFERENCES}

Abdel-Gaber, A.M., B.A. Abd-El Nabey, I.M. Sidahmed, A.M. El-Zayady and M. Saadawy, 2006. Effect of temperature on inhibitive action of damsissa extract on the corrosion of steel in acidic media. Corrosion, 62: 293-299.

Abiola, O.K. and N.C. Okafor, 2003. Corrosion inhibition effect of Cocos nuciferal juice on mild steel in 5\% hydrochloric acid solution. Sci. Afr., 2: 82-82.

Abiola, O.K., N.C. Oforka and S.S. Angaye, 2004. Corrosion behaviour of aluminium in hydrochloric acid $(\mathrm{HCl})$ solution containing mercaptoacetic acid. Mater. Lett., 58: 3461-3466.

Abiola, O.K., N.C. Oforka, N.M. Nwinuka and E.E. Ebenso, 2007. Eco-friendly corrosion inhibitors: The inhibitive action of Delonix regia extract for the corrosion of aluminium in acidic media. Anti-Corrosion Methods Mater., 54: 219-224. 
Ajayi, O.O., O.A. Omotosho, K.O. Ajanaku and B.O. Olawore, 2011. Degradation study of aluminum alloy in $2 \mathrm{~m}$ hydrochloric acid in the presence of Chromolaena odorata. J. Eng. Applied Sci., 6: 10-17.

Assaf, F.H., M. Abou-Krish, A.S. El-Shahawy, M.T. Makhlouf and H. Soudy, 2007. The synergistic inhibitive effect and the thermodynamic parameters of 2 (2- hydroxylstyryl) pyridinium-N- ethyl iodide and some metal cations on the acid corrosion of lowcarbon steel. Int. J. Electrochem. Sci., 2: 169-181.

Diaz-Ballote, L., J.F. Lopez-Sansores, L. Maldonado-Lopez and L.F. Garfias-Mesias, 2009. Corrosion behavior of aluminum exposed to a biodiesel. Electrochem. Commun., 11: 41-44.

El-Etre, A.Y., 2003. Inhibition of aluminum corrosion using Opuntia extract. Corrosion Sci., 45: 2485-2495.

El-Sayed, A.R., A.M. Shaker and H.M. Abd El-Lateef, 2010. Corrosion inhibition of tin, indium and tin-indium alloys by adenine or adenosine in hydrochloric acid solution. Corrosion Sci., 52: 72-81.

Haque, M.M. and A. Sharif, 2001. Study on wear properties of aluminium-silicon piston alloy. J. Mater. Process Technol., 118: 69-73.

Haque, M.M. and M.A. Maleque, 1998. Effect of process variables on structure and properties of aluminium-silicon piston alloy. J. Mater. Process Technol., 77: 122-128.

Iwu, M.M., 1993. Handbook of African Medicinal Plants. 1st Edn., CRC Press, Boca Raton, FL., ISBN-10: 084934266X, pp: 464.
Mathur, P.B. and T. Vasudevan, 1982. Reaction rate studies for the corrosion of metals in acids. I. Iron in mineral acids. Corrosion, 38: 171-178.

Mishra, A.K. and R. Balasubramaniam, 2007. Corrosion inhibition of aluminum alloy AA 2014 by rare earth chlorides. Corrosion Sci., 49: 1027-1044.

Noor, E.A. and A.H. Al-Moubaraki, 2008. Corrosion behavior of mild steel in hydrochloric acid solutions. Int. J. Electrochem. Sci., 3: 806-818.

Oguzie, E.E., 2005. Inhibition of acid corrosion of mild steel by Telfaria occidentalis. Pigment Resin Technol., 34: 321-326.

Okafor, P.C., E.E. Ebenso and U.J. Ekpe, 2010. Azadirachta indica extracts as corrosion inhibitor for mild steel in acid medium. Int. J. Electrochem. Sci., 5: 978-993.

Orubite, O.K. and N.C. Oforka, 2004. Inhibition of the corrosion of mild steel in hydrochloric acid solutions by the extracts of leaves of Nypa fruticans Wurmb. Mater. Lett., 58: 1768-1772.

Roberts, J.D. and M.C. Caserio, 1979. Basic Principles of Organic Chemistry. 2nd Edn., W.A. Benjamin Inc., California.

Umoren, S.A., I.B. Obot and E.E. Ebenso, 2008. Corrosion inhibition of aluminium using exudate gum from Pachylobus edulis in the presence of halide ions in HCl. E-J. Chem., 5: 355-364.

Umoren, S.A., I.B. Obot, E.E. Ebenso and N.O. ObiEgbedi, 2009. The Inhibition of aluminium corrosion in hydrochloric acid solution by exudate gum from Raphia hookeri. Desalination, 250: 225-236. 